Masterman, E. "Hygiene and Disease in Palestine in Modern and in Biblical

Times." Palestine Exploration Quarterly 50 (1918): 13-20, 56-71, 112-19.

Public Domain. Digitally prepared by Ted Hildebrandt (2004)

\title{
HYGIENE AND DISEASE IN PALESTINE IN MODERN
}

\section{AND IN BIBLICAL TIMES. (Part II)}

By DR. E. W. G. MASTERMAN.

(Continued from Q.S., 1918, p. 20.)

\section{CHAPTER II--The Climate and Water Supply in relation to Health} and Disease.

IT is not always realized that Palestine belongs to the sub-tropical zone, and lies farther south than not only every part of Europe but also of most of Morocco and Algiers, of all Tunis, and of the whole of the United States of America with the exception of Florida and parts of Texas and Louisiana. The latitude of Jaffa $\left(32^{\circ} \mathrm{N}\right.$.) is practically that of Amritsar in India and Shanghai in China. Moreover, in the great central rift of the Jordan Valley the climatic conditions must be described as tropical.

The land as a whole is fairly well supplied with rain, but the rainfall is very unequally distributed throughout the year, extending as it does over little more than six months. January, February, December and March are--in this order--the wettest months; there may be fairly heavy showers in October, November, April and, exceptionally, even in May. It is very unusual for any rain to fall in June, July, August and--except quite at the end of the month-in September. The amount of the rainfall is liable to considerable annual fluctuations and varies with the altitude. In Jerusalem, regular daily observations have been taken since 1860 . The heaviest season's rainfall was 42.95 inches in 1877-78, and the lightest 12.5 inches in 1869-70. The mean annual fall is about 26.5 inches. There seem to be cycles of greater and lesser falls, dry spells and wet coming in groups, but no definite rhythm has been observed. In the Maritime Plain, observations have been taken at Jaffa (P.E.F.) and at the German colonies of Sarona and Wilhelma, and in the 
Jordan Valley at Tiberias (P.E.F.) and at the Jewish colony of Melhamiyeh. The rainfall in the Maritime Plain is less than in Jerusalem--perhaps about 25 per cent. less--and that in the neighbourhood of the Lake of Galilee still less. Fortunately, these regions are far less dependent upon rainfall than the mountain districts. We have no regular observations recorded in the Dead Sea district, but the rainfall is very much less than in any other part of Western Palestine. On the edge of the eastern plateau there is a rainfall comparable with that on the highlands to the west, but it is only a fringe of a few miles which is so benefited. Where once the water-parting is passed and the gentle eastward slope begins, the rainfall rapidly diminishes in amount, and it is very scanty indeed east of the Hedjaz Railway.

In the late summer heavy clouds come up from the west, and during many nights the higher lands--especially in the north--are drenched in "dew" which does much to fatten the grapes and olives.

In the highlands the springs, though not infrequent, are seldom copious, and in many parts the people of the land have from early historic times resorted to cisterns to store the rain, both for their domestic use and for their vineyards. In Jerusalem, the water of the intermittent spring 'Ain Umm ed-Deraj, "the Virgin's Spring " (Gihon of the Old Testament), and of the deep-lying spring in Bir Eyyub (En-Rogel of the Old Testament) is brackish and impregnated with sewage. I have examined samples of both these waters and found abundant chlorides, free ammonia and nitrites. The main source of drinking water is consequently the numerous rainfilled cisterns--public and private--which have been excavated in the rock or, in parts of the city, in the overlying soil. In Roman times--perhaps even somewhat before--two systems of aqueducts, known respectively as the "High Level" and "Low Level" aqueducts, brought water from the neighbourhood of Wady Artas, where to-day the three great reservoirs known as "Solomon's Pools" now much out of repair, bear witness to the thoroughness of these great "waterworks." Wady Artas is $7 \frac{1}{2}$ miles directly south of Jerusalem, but the low level aqueduct, which alone remains more or less complete, ran 13 miles along the hill sides to reach the city. Two additional systems of aqueducts brought a supply also to these pools, a chain of wells connected up by an aqueduct, known as a khariz, which enters the Wady Artas by a deep rock-cut tunnel, and an aqueduct, similar in construction to the low level aqueduct, which 
runs 28 miles along the hill sides from Wady Arrub--only 5 miles to the south in a direct line.. Both these extensions have been long out of repair, but from the springs in Wady Artas, by utilizing the low level aqueduct in part and replacing it with a 4-inch iron pipe elsewhere, a feeble stream of water still (at any rate before the war) reaches Jerusalem. From this pipe the inhabitants of the city are able to fill their vessels with water of a fair quality, but it is a poor enough supply for a great city. Before this 4 -inch pipe supply was introduced, an attempt was made to supply the needs of the city-then urgent through a poor season's rainfall--by bringing water in tanks by rail from the spring at Bittir--the next station to Jerusalem on the Jerusalem-Jaffa Railway. European residents were accustomed in years gone by to have water brought in jars or tins from the abundant fountain at 'Ain Karim, but this has often proved unsatisfactory as the bearers are untrustworthy.

As far as health is concerned there is not much wrong with well-stored cistern water. It is a little "flat" but has none of the disagreeable taste of rainwater in European cities, which is contaminated by a smoky atmosphere. Careful people ensure cleanliness of the roofs by allowing the first day's rainfall in each season to run away for a few hours. Cisterns must be periodically cleaned out, but it is surprising how small is the sediment deposited in even the largest cistern, where only the roof-water is collected. Most cisterns are rock-cut and carefully cemented with an impermeable cement, in the making of which the ground-up fragments of broken--often ancient--pottery are used. Water so stored, if originally pure, keeps sweet and good for a long while and, when the sediment is settled, is quite bright and clear, although a Pasteur filter shows that there remains constantly a small quantity of undissolved earthy impurity. In some respects, the system of private cisterns is probably safer than a doubtfully-managed public supply. A water-borne disease, such as enteric fever, cannot be carried all over the city. On the other hand, the small cisterns in the houses of the poor not infrequently leak, and those in the city, being often made in the soil, may become infected with sewage. They are also mostly open and, on this account, liable to contamination from many sources. Mosquitoes-Anopheles, Culices and Stegomeyer--breed in them in countless numbers, and the Anopheles are especially dangerous as the carriers of malaria. Cisterns should be systematically inspected, repaired and kept closed to the entry of mosquitoes. The only satisfactory plan 
is to provide them all with pumps instead of the primitive handbuckets let down through a wide, open well-mouth.

The Syrian native esteems "living" (spring) water very highly, but I have known people, accustomed to the soft rainwater of Jerusalem, who were digestively upset by drinking from the beautiful springs of Nablus, the water of which is very hard from a high percentage of lime and magnesium salts.

In the villages water is, if possible, brought from springs, even at a considerable distance, for drinking purposes, but in the late summer in many places the fellahin and bedawin have to make shift with water of a very inferior quality, obtained from anywhere they can get it.

With regard to the temperature, there is a great difference between various parts of the land. Upon the high mountain plateaux of Judaea and Galilee, in parts of Central Palestine, and in much of the higher lands east of the Jordan, the winter months are bracing, though the spells of heavy rain, lasting often a week or more at a time, are trying in a land where the dwellings are built rather for heat than cold, and where fuel is scarce. To many of the poor the winter is a time to be endured with the reflection that it does not always rain. Between the bouts of rain are spells of bright sunshine and pleasant warmth. At times at Jerusalem, Hebron, and such mountain elevations, snow falls heavily, and occasionally lies on the ground for some days. It is welcomed by the agriculturalists, as the slowly melting snow thoroughly moistens the soil.

The mean temperature in the shade in Jerusalem during the three colder months (January, February and March) is $48^{\circ} \cdot 7 \mathrm{~F}$.; in the Maritime Plain (Wilhelma) $56^{\circ} \bullet$, and by the Jordan (Kasr Hajla) $69^{\circ} \cdot 2$. During the six months for May to October (inclusive) the mean in Jerusalem is $71^{\circ} \cdot 6$, in the Plains $76^{\circ} \cdot 9$, and by the Jordan $91^{\circ}$, but this hardly conveys an idea of the actual heat experienced. The mean of the maximum temperatures in the shade of the four hottest months is $84^{\circ} \cdot 3$ in Jerusalem, $96^{\circ} \cdot 4$ in the Plains, and $112^{\circ} \cdot 5$ at the Jordan. In Jerusalem itself, though temperatures over $90^{\circ}$ are common in the summer, temperatures over $100^{\circ}$ are infrequent.

The heat in the higher parts of Palestine is much mitigated by the cool westerly breezes which, with considerable regularity, blow from the middle of the forenoon until some time near sunset, and a north-westerly breeze is very common all the summer night, 
making the hours of sleep refreshing. The most unhealthy and disagreeable days are those when the dry, hot sirocco blows from the south-east ("a dry wind of the high places in the wilderness," Jer. iv, 11), sometimes for several successive days and nights. At such times those who have good stone houses keep the windows and doors closed, and to step outside from such a house is like stepping into the neighbourhood of a furnace. The wind is intensely dry and, at times, loaded with fine desert dust, producing a haze; vegetation languishes, the leaves droop, and most people--especially, perhaps, Europeans--feel varying degrees of discomfort. During and after a bout of such a wind, the increase in "fever" and other illnesses is marked. May, just after, and September and October just before the rains, are the worst months. In midsummer sirocco is rare, and in the winter the south-east wind, though dry, is cold and bracing.

Taking Palestine as a whole, for those who do not mind a fairly high temperature in summer, the clear pure air and cloudless sunshine are very enjoyable. Compared with Egypt the highlands of Palestine enjoy a better summer climate for Europeans, though falling far short of some parts of the Lebanon. But even so, in my experience, all the Europeans I have known have been benefited by occasional change to the more temperate zone, and some ladies find residence in high altitudes, such as Jerusalem, trying to the nervous system. In winter the coast and the Jordan Valley, e.g., Tiberias and Jericho, are delightful; the latter, however, for three or four months only, and even then special precautions must be taken against malaria.

Mention must be made here of local means provided by nature of treating disease. Many have found the Dead Sea water beneficial for rheumatism, but more definitely medicinal in their properties and more sanctioned by the custom of centuries, are the hot sulphurous springs which occur at many places in the land. The groups of springs at Tiberias, the valley of the Yarmuk, and in the Wady Zerka Ma'an, a valley opening into the Dead Sea from the east, were all famous in Roman times as health resorts, and are all still used by the indigenous inhabitants. Only at Tiberias has any attempt been made at providing accommodation for the bathers, and that is ill-managed and far from clean. It is to be hoped that any new regime in Palestine will recognize the value of these sites for the sick, and make arrangements that they may be used to full advantage under proper medical supervision. 
The question may well be asked at the present time how far has Palestine a climate suitable for Europeans wishing to make permanent homes there? At present malaria and other diseases are recurring scourges which greatly increase the danger and discomfort of those who would live there. But supposing these can be in places banished and in others mitigated, what is likely to be the effect on the European and his family who make the land their home? My impression is that in the higher mountain regions many Europeans may with care live comfortably, if they learn to restrain their energies, especially in the hot months, and their children can, with special precautions, be reared in health. I have my doubts as to whether a succession of generations, where the children do not have the benefit of visiting Europe for a period of years in their youth--as is the case with most Europeans to-daywould grow up such a sturdy stock as those reared in northern climes. In the Maritime Plain European families, especially young children, would probably suffer from the much prolonged sub-tropical heat, and visits to the highlands part of each summer is desirable if possible. Schools for such children might advantageously be situated in the mountains.

Most of the Jordan Valley is quite unfit for European families. It is intensely malarious, and this disease is unlikely to be eradicated here. Though the individual--the hardy adult workman, whose work lies there--may, by living in a mosquito-proof house and taking quinine, protect himself, it is no place for a family except for a few months in winter. The families of those whose work lies there should live in the mountains, and ready means of access, by tram or train, should be provided for the overseers. In the deepest parts of the Jordan Valley, e.g., round Jericho, etc., the actual manual labourers should, I suspect, be of negro stock, as are so many of the people there to-day.

\section{CHAPTER III.--The Common Diseases of Palestine and Syria.}

The most characteristic and important of the diseases of Palestine is Malaria in its various manifestations. Practically speaking, it occurs all over the land and affects every class of its inhabitants. It is very prevalent in Jerusalem, especially in late summer. Recent investigations have shown that during these months (August to October) 27.30 per cent. of all the children actually attending school have malarial parasites in their blood; and on examination, 
the blood of 7,771 persons of all classes and conditions revealed parasites in 26.7 percent. The percentages were remarkably divided, being 40.5 per cent. among the poor Jews, 31.1 per cent. among the Moslems, 16.4 per cent. among the native Christians, and 7.2 per cent. among the Europeans. Practically, the percentage is an index of social environment and hygienic surroundings, the Europeans in particular having learned the lesson of prevention and early cure. Malaria occurs, though as a rule to a lesser extent, in all the towns and villages in the mountain region, especially those bordering on the Jordan Valley.

The incidence of malaria is now known to depend very largely on the water supply of a district and the nearness to areas where the fever lingers longest throughout the year, because the healthy are infected from the sick through certain kinds of mosquitoes, which pass the larva and pupa state of their lives in water. Five species of the sub-family Anophelinae have been identified in Palestine, all of which are probably malarial-parasite carriers, viz., Anopheles Maculipennis (the common Anopheles of Jerusalem), Pyretophorus Palestinensis, Pyretophoris Sergentii (only as yet identified in Galilee), Myzorhynchus Pseudopictus (common in the Huleh marshes), and Cella Pseudopictus. Of these the first two are the most widely distributed and important. The usual situations of breeding of the larvae of these mosquitoes are the marshy pools and sluggish streams of the low lands; in the neighbourhood of Jaffa and at many places on the coast, especially around Caesarea and the neighbouring district, such semi-stagnant pools occur in numbers. In Jerusalem, the larvae of the two first-mentioned varieties breed in countless numbers in the semi-closed rainwater cisterns attached to almost all the houses, and it is therefore little wonder that malarial fevers are there continuously propagated. There are many villages and small towns where there are no suitable breeding grounds, and in such places malarial fevers are rare. The forms of malaria are the Tertian (occurring every third day, that is, with one day's interval), the Quartian (with two days' interval), and the Tropical, or double Tertian, where the fever is remittent but not intermittent. The only satisfactory means of distinguishing the three forms lies in microscopical examination of the blood in all cases. This we did for one whole year in all cases coming to my hospital, as far as possible on the first occasion of any given attack of fever. Out of 2,166 such cases, we found parasites in $\mathbf{4 6 . 5}$ per cent., and of these cases 
25.5 per cent. had Tertian parasites, 27.4 per cent. Quartian parasites, and 47.1 per cent. Tropical or malignant malarial parasites many cases were doubly infected, and some had all varieties at one time. Almost all the Tropical cases occurred in the hot months, July to November, and no fresh infections occurred in the cool weather, because this particular parasite cannot develop in the body of the mosquito in so cool a temperature. Were it not for the continual re-infection of the inhabitants by people returning fever-stricken from the tropical Ghor, this, by far the most dangerous form of malaria, would die out in the mountains. The closing of cisterns, the destruction of the larvae by putting a small quantity of petroleum on the surface of the water (which in no way spoils the water for drinking purposes if the water is taken from some depth by means of a pump, and in any case evaporates in a few hours), and the isolation of the sick within mosquito-proof curtains or buildings, are some of the means which have already been introduced to diminish infection. The prophylactic use of quinine has also been tried with considerable success. In the case of many European houses, the use of wire netting for windows and doors has greatly reduced the number of these pests and almost entirely prevented malaria. The systematic carrying out of well-recognized measures might reduce malaria, in Jerusalem at any rate, to a minimum The loss of life, particularly infant life, through malaria is terrible; in many districts every infant in arms will be found to have an enormous "ague cake " (enlarged spleen), to be anaemic and often dropsical. The anaemia caused by malaria lays the victims open to infection by various other diseases on account of their reduced constitutional resistance, and makes them anxious cases for surgical operations as they are specially liable to haemorrhage. Malaria is thus directly and indirectly responsible for more deaths among children and young adults in many parts of these lands than any other disease. During recent years a number of cases of Blackwater fever have occurred: they have been almost exclusively among Europeans-Germans and immigrant Jews--and chiefly in the "colonies" around Jaffa or in the upper end of the Jordan Valley. In some years the disease has assumed a great virulence and the mortality has been very high. Even in Jerusalem cases occur from time to time among the residents.

Enteric fever, always endemic, at times occurs in epidemics. It is particularly fatal to Europeans; doubtless many of the native 
children suffer from mild attacks in infancy and are, later in life, more or less immune. Of other fevers, typhus, influenza, and (on the coast) Dengue fever all occur in epidemics. Sporadic cases of Malta fever are seen at times, and also Spirillum (relapsing) fever. Measles, rubeola, mumps, whooping-cough, and chicken-pox are almost always to be found among the children; the first-mentioned at times bursts forth with startling severity.

Smallpox when it sweeps through the land, has a very high mortality; vaccination is but half-heartedly carried out even in the large towns, and scarcely at all in the villages. I have known cases of unvaccinated Europeans-travellers and residents--being fatally attacked. Inoculation is still resorted to at times, with terrible results.

Scarlet fever appears to have been recently introduced, and its toll of victims in the towns has been enormous.

Diphtheria occurs from time to time, but probably less so-paradoxically enough--than in the more sanitary cities of Europe.

Dysentery is most commonly a complication of malarial attacks, but acute (amoebic) dysentery also occurs not infrequently, a large proportion of the cases being fatal. Tropical abscess of the liver is by no means uncommon, as a sequela of dysentery.

Cholera, known to the natives as howa el-asfar ("the yellow wind"), appears in severe epidemics at intervals, with an enormous mortality. In nothing does the fatalism of the ignorant natives appear more prominently than in their attitude towards this disease. In spite of all warnings, they will wash the clothes of cholera patients in the village water-supply; at Tiberias, during the terrible epidemic of 1902, many of the people could not be induced to drink the boiled water freely and liberally supplied to them by the resident Scotch doctor, but used this for washing their clothes and drank of the sewage-infected lake-water at their doors. It is not wonderful that the epidemic decimated the town. Fortunately, epidemics of this disease have been rare during the last half-century.

Plague. has not occurred in epidemic form in Palestine since the first third of the nineteenth century, though sporadic cases have been detected and isolated at the ports; in earlier ages it swept over the land with terrible effect.

Erysipelas is by no means uncommon among the town-dwellers, many cases contracting infection at the site of the "issues" the people make and keep permanently open on their arms and elsewhere 
with the idea of benefiting their chronic eye-diseases. Tetanus occurs occasionally, and cases of hydrophobia from the bites of camels, jackals and cats, as well as pariah dogs, occur annually. The Turkish Government, through the local authorities, assist all such cases, when needing financial help, to go to Egypt or Constantinople for treatment by the Pasteur method, and just before the war the "International Health Bureau" established a small "Pasteur Institute" in Jerusalem, but the fellahin have but little belief in any European assistance in this disease.

Acute rheumatism is fairly common, and is responsible for a large proportion of the cases of valvular disease of the heart. Such cases do badly on account of the poor food, the anaemia produced by malaria, and, in the cases of women, the very youthful age of marriage, frequent child-bearing, and hard life generally. The closely allied disease, chorea (St. Vitus's dance), is not uncommon.

Chronic rheumatoid arthritis is commoner among the Jews and other European residents than among the fellahin. Next to malaria the disease germ most responsible for death in Palestine and Syria to-day is Tubercle. The increase in tubercular disease in the land during the last few years has been appalling. Tubercular disease of the lungs (phthisis), of the bowels (tabes rnesenterica), of the bones and joints (producing caries of the spine, hip disease, etc.), and of the lymphatic glands, occur everywhere. Cases of Phthisis (consumption) are often exceedingly acute, even when pure air and a semi-outdoor life are secured. This is due, doubtless, in many instances, to the mistaken kindness of friends, who quietly allow patients to refuse nourishment when there is a disinclination for food. There is a growing dread of infection in this disease, and many poor sufferers are shockingly neglected by their relatives, who are afraid to associate with them. There might be a fine field for philanthropic effort in the establishment of efficient sanatoria for such cases. There is already one such in Syria, in the mountains north of Beirut. The increase in phthisis is no doubt partly due to the great number of cases of this disease which have been sent to the land from other countries. Jews from Russia, so infected, used constantly to arrive, advised by their doctors to try the pure air of Syria. Doubtless, too, many dwellings become riddled with tubercle bacilli from cases of advanced disease, who pass months crouched up in dark corners, spitting infective sputum all over the floor, and in a state of filth and neglect. A great deal of tuberculous 
meat, which is rejected as tarif (ritually "unclean") by the Jews, is freely sold among other classes. Oxen and cows are not readily killed while useful, and their failure of strength in ploughing or in milk-production is often due to tuberculous disease; they are thus peculiarly liable to come into the hands of the butcher in that condition. With respect to tubercle of glands, bones and joints, it is safe to say that the majority of the severe operations performed by surgeons in Palestine are for the treatment of such conditions. Caries of the spine, producing the crook-backedness of Lev. xxi, 20, is by no means rare. It would appear to be considered a merit among the Jews for a man to marry such a deformed woman.

Leprosy is not a common disease but it infects all classes-Moslems, Jews and Christians: there are in all Palestine not more, perhaps, than 250 lepers, most of them segregated in Jerusalem, Ramleh, Nablus, or Damascus, where they live in houses provided by the Government. The fact, however, which the writer has recently observed, that a good many cases are to be found unsuspected among the villagers in some parts of the land, makes the above estimate a little uncertain. The disease occurs very sporadically without any evident cause. For practical purposes it may be considered incurable, though the rare cases of the pure "anesthetic" form--where the peripheral nerve trunks are chiefly involved--live many years, and, after a time, the disease may cease to progress. Tubercular or "mixed" forms, in which the skin is invaded by nodules of new inflammatory deposit produced by the presence of masses of leprosy baccilli, are much more rapidly fatal. Seven or eight years is the average length of life from the time when the symptoms are first recognised. The later stages of this disease are, in this--the common--form of the disease, attended by horrible mutilation. The fingers and toes, and sometimes portions of the arms and legs, ulcerate away; the eyes are always affected and the eyelids are distorted: the nose, cheeks, mouth and especially the palate, are swollen and ulcerated; the face gradually loses it expression, and often becomes an object of horror; the voice becomes hoarse, and, at times, reduced to a whisper, through ulceration of the vocal cords. In the last stages the man is really a "mass of corruption," but fortunately for him the intellectual powers are gradually dimmed, and the poor victim does not realize his position. In purely "anaesthetic" cases unsightly contractions of the hands and feet due to paralysis of certain groups of muscles occur, and 
the condition, though permanent, sometimes remains without further progressive deformity for years. The disease, though in a low degree infectious, is not hereditary, and the children of lepers, if isolated from their parents early enough, may entirely escape the disease. This has been demonstrated many times in connection with the Moravian Leper Hospital in Jerusalem.

Rickets is a disease by no means uncommon in the towns, particularly among some classes of Jews. Infantile diarrhoea is a cause of great mortality. Syphilis, while by no means so prevalent as in European lands, is not uncommon among the town-dwelling Moslems of the middle and upper classes, but on the whole it is of rather a mild type. The relative infrequency of this disease has without doubt much to do with the rarity of chronic nervous diseases such as locomotor ataxia.

Nervous diseases as a whole are much less prevalent among the indigenous inhabitants of these lands than in the homes of higher civilization and more strenuous life. Hemiplegia, due to arterial sclerosis or embolism, infantile paralysis, epilepsy, and paralysis agilans are all, however, fairly frequently met with. Among members of the Jewish race, hysteria, hypochondriasis, sciatica and other neuralgias and migraine are all common.

Diabetes appears to be peculiarly common among this people. The writer has, however, seen several cases among Armenians and also, to a less extent, among the native Syrian Christians and even the fellahin. Diabetic gangrene is a common complication. Reference has previously been made to the extreme prevalence, among all classes, of chronic dyspepsia. Haemorrhoids (piles), due to portal congestion, are very common, particularly among the Jews, who are accustomed to the regular use of alcohol. Appendicitis is a rare disease among the bedawin and fellahin; among foreign residents it is quite as common as in home lands.

Intestinal worms of all sorts are frequent in every class. "Round worms" occur in some individuals in such quantities as to give rise to the most alarming symptoms--suggestive even of peritonitis. Tape worm (Taenia saginala) is exceedingly common, and difficult of real cure. It is introduced by means of under-cooked (diseased) meat, and it is noticeable that the Jews, although their meat is inspected by butchers certified by the Rabbis as competent, are very liable to it. Hydatid disease, due to the Taenia echinococcus, is by no means unknown. These are not however the only "worm- 
like" human parasites in Palestine. Wounds and "running ears" not uncommonly become full of maggots; ticks from dogs and horses occasionally attach themselves to the skin of the negligent; leeches (Limnatis nilotica), which abound in many wayside springs, are in some districts not uncommonly introduced with the drinking water, lodging themselves at times in the mouth, naso-pharynx, or larynx and giving rise to intermittent buccal haemorrhages, and in some cases to extreme dyspnoea. The "guinea worm" (Dracontiasis etedinensis), though almost certainly not indigenous, is not uncommonly found in the feet and legs of those who come from Arabia or Central Asia.

With regard to non-tubercular Lung diseases, spasmodic asthma is very prevalent in Jerusalem; pneumonia is a common cause of death, especially among the bedawin and the fellahin; pleurisy and empyema are likewise frequently met with. Chronic bronchitis and emphysema are common, the latter being sometimes due to the excessive use of the narghile ("hubble-bubble").

Bright's disease and, in some districts, calculus of the kidney and bladder, are all familiar diseases, even in children.

True Cancer (Carcinoma) in all its forms appears to be less common among the natives of this land than in our home lands, though evidently the climate has nothing to do with this, because Europeans suffer from it quite as frequently as in Europe. Sarcoma is found in all classes.

Congenital deformities--club feet, cleft palate, hare-lip, abnormal numbers of fingers and toes, etc.--all occur much as in Europe. There is no doubt that many children with severe congenital deformities are "put away" at birth. With regard to supernumerary fingers and toes, there appears to be a feeling that to remove such, even when very unsightly and worse than useless, is an impious act. Hernia, both congenital and acquired, is frequently met with, and in recent years great numbers of people all over the land have submitted to "radical cures"; they do not take kindly to trusses.

Skin diseases, so often a result of continued want of personal cleanliness, are very common. Eczema, lichen, impetigo contagiosa, ringworm, favus and scabies are ever present in all the town population. Herpes, erythema nodosum, urticaria, and lupus also occur. Oriental boil--the so-called "Aleppo button"--is extremely frequent in Aleppo and its neighbourhood, and also at Baghdad; but cases of this disease in Palestine are almost always from these localities. The writer never saw a genuine case which originated in Palestine. There is a peculiar eruption known as the "Jericho boil," 
which is common in the summer months in the neighbourhood of Jericho and among some of the bedawin living near the Jordan. In its chronic nature and subsequent scarring, it bears some resemblance to the true Oriental boil. The destruction of tissue is, however, much less, the lesions are usually multiple, and they are by no means exclusively on the exposed parts of the body.

Eye diseases are, and probably always have been, very prevalent in the Holy Land. The great majority of the cases of blindness are due to the results of acute ophthalmia or to smallpox; others are from injuries, cataract, glaucoma, or leprosy. Ophthalmia neonatorum (a common cause of blindness among infants in Europe) is exceedingly rare in Palestine.

The number of blind beggars about the towns is extraordinary; among the Moslems they occupy a privileged position, being employed to walk in front of funeral processions, chanting the Qur'an, led by a boy who can see; they also make similar recitations at the graves, being so employed because their condition is supposed to render them safe companions to the women-mourners who congregate there. They are prepared carefully for their duties by a shaikh, who ensures that they know the passages of the Qur'an correctly.

Among all classes these beggars receive a considerable degree of compassion and charity, and they have, in this respect, a better time than many equally poor who suffer from other diseases--except, perhaps, lepers.

The prevalent Ophthalmia of Palestine is ascribed by the natives to figs or prickly pears (cactus), and by Europeans to dust, flies, dirty water, etc. Until recent years Egyptian (and Palestinian) ophthalmia (acute muco-purulent conjunctivitis) was supposed to be something sui generis, but recent investigation has shown that this disease is due to the same specific germs as the ophthalmia of Europe. Four bacilli have been identified as commonly occurringthe gonococcus, the pneuniococcus, the Morax-Axenfeld, and the KochWeeks bacillus. The first two are answerable for a considerable proportion of the most severe cases, in which the cornea becomes ulcerated and the whole eye sometimes becomes destroyed in a few hours. The Koch-Weeks bacillus is the special cause of the great exacerbation of ophthalmia (66 per cent. of all cases, Butler) which occurs annually in July and October. Although the epidemic is in these months, the severest cases often occur later, in: November or even December. Closely associated with this acute ophthalmia, though probably an entirely distinct disease, is the widely prevalent 
trachoma, or "granular lids." This is the chief cause of defective sight and chronic filthy eyes; it appears to be a disease for which the Semitic races have a special proclivity. Like the ophthalmia mentioned above, it is, in its early-stages, highly infectious, and it is the commonest thing to find every member of a numerous family suffering from this unsightly complaint. The disease frequently begins insidiously, and is hardly noticed until a thickening of the upper lid, giving the appearance of the eye being half closed, and a smarting of the lids calls attention to it. In severe cases the whole of the conjunctiva lining the eyelids is found to be covered with "granulations" varying in size from a pin's head to a hemp seed or even larger. The "granulations," when neglected, are disastrous to the eye. In time they produce (directly or indirectly) "pannus," a kind of opaque growth over the cornea and--more serious still--these inflammatory growths commence, after a time, to cicatrize, and in so doing cause the eyelashes to become turned inwards towards the eye (trichiasis). These inverted eyelashes, by constantly playing up and down against the already irritated cornea, set up chronic inflammation, causing it to lose its transparency and leading gradually to diminishing sight and eventual blindness. The proportion of people with defective sight is enormous, and in many districts it is the exception to find a person with two really sound eyes. Among the middle-aged most eyes will be found to have upon their corneae white patches (leucomata), the cicatrices of old ulcers, or a general loss of transparency due to trachoma, or to be suffering from a chronic discharge of muco-pus from the eyelids. Flies, though not the real cause of these diseases, without doubt act as carriers of infection from the diseased eyes to the sound, and this is more easily done because the afflicted, especially the young children, do not seem to mind the dozens of flies which collect upon their discharging lids. Loss of sight, which to us seems such a terrible affliction, in the East is taken with extraordinarily stoical impassiveness. One old Moslem, for example, who had travelled far to seek the advice of a British practitioner, when told that nothing could be done, merely exclaimed "el hamd el'illah" ("the praise to God!").

Sunstroke, especially among children, is by no means uncommon. Many Europeans get mild attacks from the heat in the Ghor.

Serpents' bites are fairly frequent, and in the Jordan Valley not seldom fatal; the majority of the snakes in the land, however, are harmless. Scorpions abound, but their stings, though painful, 
are not usually dangerous; a weakly child may die from one unusually severe.

Various forms of Idiocy and Insanity are by no means uncommon, but suicide is distinctly rare. Idiots and the chronically weak-minded are treated with a certain respect and kindness, their minds being conceived of as engaged elsewhere than on earth. The acutely insane are frequently treated with great harshness-beaten, for example, or chained up in darkness and seclusion--with a view to driving out the supposed demon who causes the affliction.

A word may be added in conclusion regarding Childbirth. The age of marriage is very early in the Orient--twelve. or thirteen is no uncommon age for a girl to be married and even to become pregnant. Childbirth among the bedawin and fellahin is a very primitive affair, and labour is short and easy; even when the mother is immature, the worst, as a rule, that happens is the death of the infant at birth. In the towns, too, the "uncivilized" Arab women and the Jewesses have easy labours. European doctors are only very exceptionally called in, as the larger towns, where such doctors reside, are also well supplied with skilful midwives. The old obstetric chair, which goes back to the most ancient times, is still in use in Jerusalem, but is now rapidly passing out of fashion. The period of suckling is long--among the Jews commonly two, and among the Moslems even three, years. Considering the hard lives and often poor fare, it is marvellous how the mothers contrive to suckle for so long, but the babies suffer terribly, and infant mortality is enormous. Abscesses of the breast are common, and if they occur in both breasts early after childbirth, the infant commonly dies. Infantile diarrhoea and dysentery and the results of malaria account for many deaths. It is quite a common thing to meet women who have had a dozen or more children, but who have succeeded in rearing but one or two. Although the parents will display a good deal of spasmodic anxiety over the infant while it is ill, they take its death with philosophic resignation. This is especially the case if the deceased is a female, for girls are not considered a subject of much congratulation, and "May God give you a boy," or "May God give you many sons," are the ordinary good wishes for a married couple. Many a wife who produces an unbroken succession of girls has a bad time of it with her husband and his relations.

\section{To be continued.)}

Please report any errors to Ted Hildebrandt at: thildebrandt@gordon.edu 